\title{
More severe hypercoagulation status, cytokine storm, and disease progression in coronavirus disease 2019 with persistent RT-PCR negative results: a multicenter prospective study
}

\section{Wei Du}

Shanghai Jiao Tong University School of Medicine affiliated Ruijin Hospital

\section{Guochao Shi}

Shanghai Jiao Tong University School of Medicine affiliated Ruijin Hospital

\section{Min Zhou}

Shanghai Jiao Tong University School of Medicine affiliated Ruijin Hospital

Yahui Liu

Shanghai Jiao Tong University School of Medicine affiliated Ruijin Hospital

\section{Gelei Lan}

Shanghai Jiao Tong University School of Medicine affiliated Ruijin Hospital

\section{Xueqing Du}

Shanghai Jiao Tong University School of Medicine affiliated Ruijin Hospital

\section{Chunrong Huang}

Shanghai Jiao Tong University School of Medicine affiliated Ruijin Hospital

\section{Ranran Dai ( $\nabla$ drrcyy@163.com )}

Shanghai Jiao Tong University School of Medicine affiliated Ruijin Hospital

Wei Chen ( $\nabla$ monbox007@hotmail.com )

Shanghai Jiao Tong University School of Medicine affiliated Ruijin Hospital

\section{Research Article}

Keywords: COVID-19, persistent negative PCR tests, disease progression, hypercoagulation, cytokine storm

Posted Date: October 2nd, 2020

DOl: https://doi.org/10.21203/rs.3.rs-85866/v1

License: (c) (1) This work is licensed under a Creative Commons Attribution 4.0 International License. Read Full License 


\section{Abstract}

Purpose: Persistent negative results (at least 3 times) of reverse transcription-polymerase chain reaction (RT-PCR) from pharyngeal swabs are not rare in coronavirus disease 2019 (COVID-19) patients, but their characteristics have not yet been well studied.

Methods: PCR confirmed, serum antibody confirmed with persistent negative PCR results, and clinically diagnosed patients hospitalized in two medical centers during February and March 2020 were included. Differences in clinical, imaging and laboratory characteristics as well as factors affecting their prognosis were analyzed.

Results: There were 114 PCR confirmed, 17 serology confirmed and 21 clinically diagnosed patients included. Time from onset of disease to the first PCR and admission were similar among the groups. Compared with PCR-confirmed patients, serology-confirmed patients were older and likely to have hypertension, vomiting, or symptoms of chest pain and dyspnea. Regarding imaging manifestations, serology-confirmed patients were more prone to pleural effusion. In addition, higher levels of C-reactive protein, neutrophil-to-lymphocyte ratio, total bilirubin, D-dimer, fibrinogen, troponin, interleukin- 6 and IL-8 were also found. Although with similar mortality, serology confirmed patients were more likely to have disease progression. High levels of D-dimer and IL- 6 were possibly the underlying factors leading to their worse prognosis. On the other hand, clinically diagnosed patients were more similar to PCR-confirmed patients.

Conclusion: Serology confirmed COVID-19 patients with at least three negative PCR results had different clinical characteristics and were likely to have disease progression, possibly due to more severe hypercoagulation status and cytokine storm.

\section{Introduction}

Since the first reported cases in December 2019 from Wuhan, China [1], an outbreak of novel coronavirus infection, named COVID-19 (coronavirus disease 2019) by the World Health Organization (WHO), has occurred. As of August 31, there have been more than twenty million confirmed infections and eight hundred thousand deaths around the world [2]. The pathogen is a new strain of RNA viruses that has not been previously identified in humans and shares $\sim 80 \%$ nucleotide identity with the original SARS epidemic virus [3].

Unlike typical severe manifestations of SARS, the clinical characteristics of COVID-19 vary among different patients [4-6]. Fever, cough and fatigue are the most common symptoms, and subpleural ground-glass opacity involving the bilateral lung is the typical imaging characteristic [3, 7-12]. However, some patients also have no symptom or mild symptoms but with marked chest imaging abnormalities $[13,14]$, and patients with no imaging abnormalities are not that rare [8]. Since the clinical manifestations of COVID-19 are highly variable, further research to characterize its clinical profile is necessary. Nevertheless, most of the studies only concentrate on the clinical characteristics of nucleic acid-positive 
patients. However, patients with persistent negative results of real-time reverse transcription-polymerase chain reaction (RT-PCR) are largely ignored. Some researchers attempted to describe the characteristics of these patients by recruiting clinically diagnosed subjects who are highly likely to be COVID-19 based on their clinical and imaging characteristics, but selection bias is an unavoidable problem [15].

Fortunately, recent studies have provided another serological assay to confirm the diagnosis of COVID-19 patients [16], making us able to analyze the characteristics of confirmed COVID-19 patients with persistent RT-PCR negative results. We found that these older patients were more likely to have hypertension, dyspnea, chest pain, vomiting, pleural effusion, severe inflammatory and cytokine responses, hypercoagulation status, liver and heart damage, malnutrition, and disease progression.

\section{Materials And Methods}

\section{Study population}

In the present prospective study, RT-PCR confirmed or clinically suspected COVID-19 patients were screened at Tongji Hospital of Tongji Medical College of Huazhong University of Science in Wuhan and Shanghai Jiao Tong University School of Medicine affiliated Ruijin Hospital in Shanghai, from February 2020 to March 2020. The study was conducted following the Declaration of Helsinki, as approved by the aforementioned hospitals. All the participants provided written informed consent.

Patients were included in this study when they met the diagnosis standard according to the practice guidance for diagnosis and treatment of novel coronavirus pneumonia in China (7th trial version) issued by the China National Health Commission, of which patients can be confirmed if they have positive RTPCR or gene sequencing results, dual positive of anti-viral immunoglobulin $M(\lg M)$ and $G(\lg G)$, transformation of negative to positive IgG, or more than four times of increased IgG titer during recovery stage [17]. Patients with initial or subsequent positive PCR results were considered PCR confirmed cases, while patients with persistent PCR results (at least 3 tests) during the disease course but positive serology results were regarded as serology confirmed cases. PCR tests were conducted every $3( \pm 2)$ days. In addition, patients with negative RT-PCR and positive radiologic findings but not tested by serological assay were also included in the analysis, namely, clinically diagnosed cases.

Patients were excluded from the study if they were participating in other clinical trials, negative results of both RT-PCR and serological assay, and rehospitalized because of positive RT-PCR results during quarantine time after discharge.

\section{Data collection}

We collected epidemiological, demographic, clinical, laboratory examination, chest imaging, and outcome data from medical records. Outcomes were followed up to March 31, 2020. All data were documented and checked by two physicians. Chest imaging evaluation was conducted by two radiologists 
independently. Clinical severity was evaluated according to standards set up by the China National Health Commission [17]. By discussion among radiologists and researchers, discrepancies were addressed.

\section{Statistical analysis}

Categorical variables are presented as a number (percentage), while continuous variables with normal distribution are expressed as the mean \pm standard deviation (SD). Ordinal variables or continuous variables inconsistent with a normal distribution were expressed as medians (interquartile ranges). Differences among the groups were compared by Fisher's exact test for categorical variables and oneway analysis of variance (ANOVA) or nonparametric Kruskal Wallis test on continuous or ordinal variables, as appropriate. Spearman correlation and logistic regression analyses were conducted as necessary. There were no missing data.

All statistical analyses were conducted with IBM SPSS, version 20.0 (IBM Corp., Armonk, NY, USA), and a p-value of $<0.05$ was considered statistically significant.

\section{Results}

\section{Demographic and epidemiological characteristics of patients.}

A total of 152 patients were included in this study, of whom 114 were PCR confirmed, 17 were serology confirmed, and 21 were clinically diagnosed (Flowchart in Figure 1). Nearly a quarter of them had exposure to known COVID-19 patients (21.1\%), and clustered cases were also common (28.9\%). The median value of nucleic acid test frequency of PCR and serology confirmed cases was five times, with the highest frequency being nine times for serology confirmed cases. The initial PCR test could pick out 92.1\% of PCR confirmed cases, and more than three PCR tests did not find more PCR confirmed patients.

The time from the onset of disease to the first PCR test or admission was similar among the groups, suggesting that there was no delay of PCR tests or therapy for these patients. No differences in gender distribution or body mass index (BMI) were found among the three groups, but serology confirmed patients were older and a longer time was needed to confirm the diagnosis (Table 1). The latter finding was possibly due to later application of the serological assay. In addition, the time from the onset of disease to the first negative PCR results was longer for PCR-confirmed patients than for serologyconfirmed patients $(24.3 \pm 9.1$ vs. $12.2 \pm 8.4, P=0.000)$, suggesting that negative results of the latter patients were not due to delay of tests.

In terms of past history, serology-confirmed patients had a higher prevalence of hypertension (34.2 vs. $64.7 \%, P=0.021$ ) compared with PCR-confirmed patients, but age was correlated with the occurrence of hypertension $(\mathrm{r}=0.318, P=0.000)$, and this difference disappeared if the effect of age was balanced via logistic regression, suggesting that the difference in hypertension prevalence could be explained by 
different age distributions. More details about demographic and epidemiological characteristics can be seen in Table 1.

\section{Serology confirmed COVID-19 patients with persistent negative PCR test results had different clinical, imaging and laboratory characteristics.}

Similar to previous reports $[18,19]$, the most common symptoms of confirmed COVID-19 patients were fever, cough, and fatigue in our study. In addition, anorexia and chest tightness could exist in more than half of COVID-19 patients. In contrast, nasal symptoms, including sneezing and nasal discharge, were rare in these patients (Table 2).

On the other hand, although the proportion of patients with dyspnea or chest pain was similar between PCR and serology-confirmed cases ( 53.5 vs. $64.7 \%, P=0.390$ ), patients with both dyspnea and chest pain were more common in serology-confirmed patients ( 13.2 vs. $41.2 \%, P=0.007$ ). Additionally, symptoms of the upper digestive tract, including nausea and vomiting, were more common in serology-confirmed patients ( 19.3 vs. 41.2 vs. $4.8 \%, P=0.020$ ). In addition, nausea was highly correlated with diarrhea symptoms in serology-confirmed cases $(r=0.701, P=0.005)$, but in PCR-confirmed $(r=0.360, P=0.000)$ or clinically diagnosed patients $(r=-0.122, P=0.620)$, this kind of correlation was weak or absent. Moreover, more severe or critical patients were found in serology-confirmed patients (35.1 vs. 64.7 vs. $23.8 \%$, $P=0.026$ ). Since older age is a critical risk factor for severe disease ${ }^{20}$, the correlation of age and severity was explored, and we found that age was correlated with the severity of COVID-19 ( $r=0.192, P=0.018$ ). Moreover, serology-confirmed patients were no longer more severe than PCR-confirmed patients if the effect of age was balanced via logistic regression analysis (OR 2.57, 95\% confidence interval (Cl) 0.89$7.41, P=0.081)$.

In terms of imaging characteristics, the most frequent presentation was bilateral involved ground glass opacity $(90.8 \%, 88.2 \%$ and $77.8 \%$ of PCR confirmed, serology confirmed, and clinically diagnosed patients, respectively), and imaging presentations of different groups were similar, except for proportion of pleural effusion, which was lower in PCR confirmed patients (1.9 vs. 12.5 vs. $11.1 \%, P=0.030$, Table 2).

Regarding laboratory indicators, serology-confirmed patients also had different features. As shown in Table 3, serology confirmed patients had higher levels of C-reactive protein (CRP), neutrophil-tolymphocyte ratio (NLR), total bilirubin (TB), D-dimer, fibrinogen (Fg), troponin, interleukin-6 (IL-6) and IL-8, as well as lower levels of hemoglobin $(\mathrm{Hb})$ and serum albumin (Alb).

\section{Serology confirmed COVID-19 patients were more likely to have disease progression.}

Although serology-confirmed or clinically diagnosed patients had similar mortality to PCR-confirmed patients, the proportion of disease progression was significantly higher in serology-confirmed cases (3.5 vs. 17.6 vs. $10.0 \%, P=0.041$, Table 2$)$. Moreover, the time of hospital stay ( $22.4 \pm 11.1$ vs. $28.8 \pm 10.6$ vs. $13.0 \pm 7.8, P=0.000)$ and from admission to cessation of oxygen support ( $17.0 \pm 13.9$ vs. $28.9 \pm 9.9$ vs. $12.0 \pm 8.3, P=0.000$ ) were also longer for serology-confirmed patients. With regard to imaging presentation, 
serology-confirmed patients were less likely to have obvious improvement (OR $0.27,95 \% \mathrm{Cl} 0.072-0.98$, $\mathrm{P}=0.047)$.

Since old age was found to be associated with disease progression [21] and serology-confirmed patients were older, logistic regression was conducted to exclude the effect of age on disease progression.

However, serology-confirmed cases were still likely to have disease progression even excluding the effect of age (OR 5.7, 95\% $\mathrm{Cl} 1.1-30.2, P=0.041$ ), indicating that there were other possible factors contributing to the disease progression of serology-confirmed patients. To identify these underlying influencing factors, laboratory indicators such as CRP, NLR, Hb, TB, Alb, D-dimer, Fg, troponin, IL-6, and IL-8 were successively included in the logistic regression model. Only the levels of $\mathrm{D}$-dimer (OR 1.23, 95\% Cl 1.04-1.46, $P=0.016$ ) and IL-6 (OR 1.05, 95\% Cl 1.01-1.09, $P=0.016)$ were associated with disease progression, and the effect of serology-confirmed cases on disease progression disappeared when they were included in the model, suggesting that more severe hypercoagulation and cytokine reaction were possibly the underlying factors contributing to the disease progression of serology-confirmed patients.

\section{Discussion}

Since the outbreak of COVID-19 in China and around the world, the nucleic acid test has been considered one of the most important gold standard methods for the diagnosis of this highly contagious disease [17, 22-23]. However, false negative results were always the most concerning issue, leading to a rapid growth of invention and evaluation of other diagnostic tools such as computed tomography and serum antibody assay $[15,18]$. In addition, repeated PCR tests of pharyngeal swabs and further specimen collection from the lower respiratory tract were also useful ways to minimize the false negative rate $[7,24]$. Nevertheless, in our clinical practice and previous case reports [14, 24-25], some symptomatic patients with CT abnormalities were continuously PCR negative for pharyngeal swabs, even with more than three tests, which was enough to detect the majority of PCR-diagnosed patients [26]. Therefore, in our study, characteristics of these patients were described, and we found that serology-confirmed patients with continuously negative PCR results were older, more severe, tending to have both symptoms of dyspnea and chest pain, and likely to have pleural effusion. In regard to outcomes, they would be in hospital longer, need more time to get rid of oxygen support, and have higher risk of disease progression, even with effects of confounding factors, such as age, excluded. On the other hand, the demographic, clinical and imaging characteristics of clinically diagnosed patients were more similar to those of PCR-confirmed patients, consistent with a previous study [27].

Until now, only some case reports have described the clinical characteristics of patients with persistent negative PCR results from pharyngeal swabs. All of these cases had fever, and patients with nausea also had diarrhea, which was consistent with our findings that fever was common and nausea was highly correlated with diarrhea [14, 24-25]. In addition, our study also found that patients with both symptoms of dyspnea and chest pain were more common in serology-confirmed cases, possibly due to hypercoagulation status, cardiac injury and involvement of the pleura, as these patients had higher levels of D-dimer and troponin as well as a higher proportion of pleural lesions. In accordance with this finding, 
one study describing the clinical characteristics of clinically diagnosed COVID-19 patients without positive PCR results reported that these patients were more likely to have dyspnea [27].

Regarding imaging characteristics, ground glass opacity was still the most common imaging manifestation for all COVID-19 patients, similar to what other studies have described [8, 28-29]. However, serology-confirmed patients were more likely to have pleural effusion, implying that pleural involvement of this subgroup of COVID-19 patients was more common than what we found in PCR-confirmed patients [30].

Factors associated with the disease progression of COVID-19 have been extensively studied [31], but no study has reported the effect of persistent negative PCR results on the disease progression of confirmed COVID-19 patients. Hence, in our study, we analyzed the effect and revealed that COVID-19 patients with persistent negative PCR results tended to have disease progression. This might be explained by older age, accompanying hypertension, more severe status upon admission and elevated CRP, NLR, IL-6, D-dimer, or troponin in these patients to some extent, since other studies previously reported effects of these factors on disease progression [32-34]. However, after excluding the effect of age, only serum levels of IL-6 and D-dimer were still associated with disease progression, implying that more severe cytokine reactions and microvascular thromboembolism might be the cause of progression in these patients. These findings were supported by a recent autopsy report for a patient with three negative PCR results from a nasopharyngeal swab, which showed that positive SARS-CoV-2 virus nucleic acid was only found in the lung for this patient, and diffuse alveolar damage, hyaline thrombus in microvessels and infiltration of inflammatory cells were also found [35].

Inevitably, there were limitations in this study. First, the number of included patients was not large enough, restricting extrapolation of our results to a larger population. Second, as an observational study, clinical, imaging and laboratory indicators were not followed up in a well-designed plan, making some results not precise enough.

\section{Conclusion}

In this study, we found a novel subgroup of COVID-19 patients who had persistent negative PCR results from pharyngeal swabs and could only be diagnosed by serological assay or nucleic acid test from lower airway specimens. They had distinct clinical, imaging, and laboratory characteristics as well as worse prognosis compared with PCR-positive patients. Their special manifestations indicated the necessity of serological assay of antibodies against SARS-CoV-2 and PCR tests from lower airway specimens. Additionally, for this kind of patient, careful monitoring and timely treatment are needed to avoid disease progression, and hypercoagulation status and cytokine storm are the most critical problems in need of close attention. As a result of limited reports and the relatively small number of these patients in our study, further studies are required to explore the characteristics and treatment strategy of these patients.

\section{Declarations}




\section{Funding}

This study was funded by Shanghai Key Discipline for Respiratory Diseases (2017ZZ02014), National Natural Science Foundation of China $(81970020,81770025)$ and National Key Research and Development Program of China (2016YFC0901104) for data collection and analysis, acquisition of nucleic acid and serum assay reagent kits, and wages of the staff.

\section{Competing interests}

No potential conflict of interest was reported by the authors.

\section{Ethics approval and consent to participate}

The study was conducted following the Declaration of Helsinki, as approved by ethics committees of Tongji Hospital of Tongji Medical College of Huazhong University of Science in Wuhan, and Shanghai Jiao Tong University School of Medicine affiliated Ruijin Hospital in Shanghai. All the participants provided written informed consent.

\section{Consent for publication}

Publication was agreed upon by all the authors.

\section{Availability of data and materials}

The datasets used and/or analysed during the current study are available from the corresponding author on reasonable request.

\section{Code availability}

Not applicable.

\section{Authors' contributions}

WD and GS contributed equally to this article. RD and WC contributed equally to this article. Detailed contributions are listed below:

WD: Conceptualization, Data curation, Formal analysis, Investigation, Methodology, Project administration, Resources, Software, Validation, Visualization

GS: Conceptualization, Formal analysis, Funding acquisition, Methodology, Project administration, Validation, Visualization

MZ: Formal analysis, Visualization

YL: Data curation 
GL: Data curation

XD: Data curation

$\mathrm{CH}$ : Data curation

RD: Conceptualization, Formal analysis, Investigation, Methodology, Project administration, Supervision, Validation, Visualization

WC: Conceptualization, Investigation, Methodology, Project administration, Resources, Supervision, Validation, Visualization

\section{Acknowledgements}

We thank the colleagues of Tongji Hospital of Tongji Medical College of Huazhong University of Science for their help in fighting against COVID-19.

\section{References}

1. JF Chan, Yuan S, Kok KH, To KK, Chu H, Yang J, Xing F, Liu J, Yip CC, Poon RW, Tsoi HW, Lo SK, Chan KH, Poon VK, Chan WM, Ip JD, Cai JP, Cheng VC, Chen H, Hui CK, Yuen KY. A familial cluster of pneumonia associated with the 2019 novel coronavirus indicating person-to-person transmission: a study of a family cluster. Lancet. 2020; 395: 514-23.

2. World Health Organization. Coronavirus disease 2019 (COVID-19) Situation Report-77. Available at https://www.who.int/docs/default-source/coronaviruse/situation-reports/20200406-sitrep-77-covid19.pdf?sfvrsn=21d1e632_2. Accessed 12 May 2020.

3. Zhang JJ, Dong X, Cao YY, Yuan YD, Yang YB, Yan YQ, Akdis CA, Gao YD. Clinical characteristics of 140 patients infected with SARS-CoV-2 in Wuhan, China. Allergy. 2020. Doi: 10.1111/all.14238.

4. Leung GM, Hedley AJ, Ho LM, Chau P, Wong IO, Thach TQ, Ghani AC, Donnelly CA, Fraser C, Riley S, Ferguson NM, Anderson RM, Tsang T, Leung PY, Wong V, Chan JC, Tsui E, Lo SV, Lam TH. The epidemiology of severe acute respiratory syndrome in the 2003 Hong Kong epidemic: an analysis of all 1755 patients. Ann. Intern. Med. 2004; 141: 662-73.

5. Peiris JS, Guan Y. Confronting SARS: a view from Hong Kong. Philos. Trans. R. Soc. Lond., B, Biol. Sci. 2004; 359: 1075-9.

6. Tsang KW, Ho PL, Ooi GC, Yee WK, Wang T, Chan-Yeung M, Lam WK, Seto WH, Yam LY, Cheung TM, Wong PC, Lam B, Ip MS, Chan J, Yuen KY, Lai KN. A cluster of cases of severe acute respiratory syndrome in Hong Kong. N. Engl. J. Med. 2003; 348: 1977-85. 
7. Long C, Xu H, Shen Q, Zhang X, Fan B, Wang C, Zeng B, Li Z, Li X, Li H. Diagnosis of the Coronavirus disease (COVID-19): rRT-PCR or CT? Eur. J. Radiol. 2020; 126: 108961.

8. Yang W, Cao Q, Qin L, Wang X, Cheng Z, Pan A, Dai J, Sun Q, Zhao F, Qu J, Yan F. Clinical characteristics and imaging manifestations of the 2019 novel coronavirus disease (COVID-19):A multi-center study in Wenzhou city, Zhejiang, China. J. Infect. 2020; 80: 388-93.

9. Yu F, Yan L, Wang N, Yang S, Wang L, Tang Y, Gao G, Wang S, Ma C, Xie R, Wang F, Tan C, Zhu L, Guo Y, Zhang F. Quantitative Detection and Viral Load Analysis of SARS-CoV-2 in Infected Patients. Clin. Infect. Dis. 2020. Doi: 10.1093/cid/ciaa345.

10. Huang C, Wang Y, Li X, Ren L, Zhao J, Hu Y, Zhang L, Fan G, Xu J, Gu X, Cheng Z, Yu T, Xia J, Wei Y, Wu W, Xie X, Yin W, Li H, Liu M, Xiao Y, Gao H, Guo L, Xie J, Wang G, Jiang R, Gao Z, Jin Q, Wang J, Cao B. Clinical features of patients infected with 2019 novel coronavirus in Wuhan, China. Lancet. 2020; 395: 497-506.

11. Chen N, Zhou M, Dong X, Qu J, Gong F, Han Y, Qiu Y, Wang J, Liu Y, Wei Y, Xia J, Yu T, Zhang X, Zhang L. Epidemiological and clinical characteristics of 99 cases of 2019 novel coronavirus pneumonia in Wuhan, China: a descriptive study. Lancet. 2020; 395: 507-13.

12. Zhao X, Liu B, Yu Y, Wang X, Du Y, Gu J, Wu X. The characteristics and clinical value of chest CT images of novel coronavirus pneumonia. Clin. Radiol. 2020. Doi: 10.1016/j.crad.2020.03.002.

13. Sivakorn C, Luvira V, Muangnoicharoen S, Piroonamornpun P, Ouppapong T, Mungaomklang A, lamsirithaworn S. Case Report: Walking Pneumonia in Novel Coronavirus Disease (COVID-19): Mild Symptoms with Marked Abnormalities on Chest Imaging. Am. J. Trop. Med. Hyg. 2020. Doi: 10.4269/ajtmh.20-0203.

14. Dong X, Cao YY, Lu XX, Zhang JJ, Du H, Yan YQ, Akdis CA, Gao YD. Eleven Faces of Coronavirus Disease 2019. Allergy. 2020. Doi: 10.4269/ajtmh.20-0203.

15. Ai T, Yang Z, Hou H, Zhan C, Chen C, Lv W, Tao Q, Sun Z, Xia L. Correlation of Chest CT and RT-PCR Testing in Coronavirus Disease 2019 (COVID-19) in China: A Report of 1014 Cases. Radiology. 2020: 200642.

16. Li Z, Yi Y, Luo X, Xiong N, Liu Y, Li S, Sun R, Wang Y, Hu B, Chen W, Zhang Y, Wang J, Huang B, Lin Y, Yang J, Cai W, Wang X, Cheng J, Chen Z, Sun K, Pan W, Zhan Z, Chen L, Ye F. Development and Clinical Application of A Rapid IgM-IgG Combined Antibody Test for SARS-CoV-2 Infection Diagnosis. J. Med. Virol. 2020. Doi: 10.1002/jmv.25727.

17. National Health Commission of the People's Republic of China. Diagnosis and treatment of novel coronavirus pneumonia (trial version seventh). Available at http://www.nhc.gov.cn/yzygj/s7653p/202003/46c9294a7dfe4cef80dc7f5912eb1989.shtml. Accessed 3 Mar 2020).

18. Zhao J, Yuan Q, Wang H, Liu W, Liao X, Su Y, Wang X, Yuan J, Li T, Li J, Qian S, Hong C, Wang F, Liu Y, Wang Z, He Q, Li Z, He B, Zhang T, Fu Y, Ge S, Liu L, Zhang J, Xia N, Zhang Z. Antibody responses to SARS-CoV-2 in patients of novel coronavirus disease 2019. Clin. Infect. Dis. 2020. Doi: $10.1093 / \mathrm{cid} / \mathrm{ciaa344}$. 
19. Zhang MQ, Wang XH, Chen YL, Zhao KL, Cai YQ, An CL, Lin MG, Mu XD. Clinical features of 2019 novel coronavirus pneumonia in the early stage from a fever clinic in Beijing. Chin. J. Tubere. Respir. Dis. 2020; 43: E013.

20. Wu C, Chen X, Cai Y, Xia J, Zhou X, Xu S, Huang H, Zhang L, Zhou X, Du C, Zhang Y, Song J, Wang S, Chao Y, Yang Z, Xu J, Zhou X, Chen D, Xiong W, Xu L, Zhou F, Jiang J, Bai C, Zheng J, Song Y. Risk Factors Associated With Acute Respiratory Distress Syndrome and Death in Patients With Coronavirus Disease 2019 Pneumonia in Wuhan, China. JAMA. Intern. Med. 2020. Doi: 10.1001/jamainternmed.2020.0994.

21. Chen J, Qi T, Liu L, Ling Y, Qian Z, Li T, Li F, Xu Q, Zhang Y, Xu S, Song Z, Zeng Y, Shen Y, Shi Y, Zhu T, Lu H. Clinical progression of patients with COVID-19 in Shanghai, China. J. Infect. 2020. Doi: 10.1016/j.jinf.2020.03.004.

22. Chu DKW, Pan Y, Cheng SMS, Hui KPY, Krishnan P, Liu Y, Ng DYM, Wan CKC, Yang P, Wang Q, Peiris M, Poon LLM. Molecular Diagnosis of a Novel Coronavirus (2019-nCoV) Causing an Outbreak of Pneumonia. Clin. Chem. 2020; 66: 549-55.

23. World Health Organization. Laboratory testing for 2019 novel coronavirus (2019-nCoV) in suspected human cases. Available at https://www.who.int/publications-detail/laboratory-testing-for-2019novel-coronavirus-in-suspected-human-cases-20200117. Accessed 19 March 2020.

24. Hase R, Kurita T, Muranaka E, Sasazawa H, Mito H, Yano Y. A case of imported COVID-19 diagnosed by PCR-positive lower respiratory specimen but with PCR-negative throat swabs. Infect. Dis. 2020: 14.

25. Winichakoon P, Chaiwarith R, Liwsrisakun C, Salee P, Goonna A, Limsukon A, Kaewpoowat Q. Negative Nasopharyngeal and Oropharyngeal Swab Does Not Rule Out COVID-19. J. Clin. Microbiol. 2020. Doi: 10.1128/jcm.00297-20.

26. Shen N, Zhu Y, Wang X, Peng J, Liu W, Wang F, Lu Y, Cheng L, Sun Z. Characteristics and diagnosis rate of 5,630 subjects receiving SARS-CoV-2 nucleic acid tests from Wuhan, China. JCI. Insight. 2020. Doi: 10.1172/jci.insight.137662.

27. Li YY, Wang WN, Lei Y, Zhang B, Yang J, Hu JW, Ren YL, Lu QF. Comparison of the clinical characteristics between RNA positive and negative patients clinically diagnosed with 2019 novel coronavirus pneumonia. Chin. J. Tubere. Respir. Dis. 2020; 43: E023.

28. Wang K, Kang S, Tian R, Zhang X, Zhang X, Wang Y. Imaging manifestations and diagnostic value of chest CT of coronavirus disease 2019 (COVID-19) in the Xiaogan area. Clin. Radiol. 2020. Doi: 10.1016/j.crad.2020.03.004.

29. Cheng Z, Lu Y, Cao Q, Qin L, Pan Z, Yan F, Yang W. Clinical Features and Chest CT Manifestations of Coronavirus Disease 2019 (COVID-19) in a Single-Center Study in Shanghai, China. Am. J. Roentgenol. 2020: 1-6.

30. Bao C, Liu X, Zhang H, Li Y, Liu J. Coronavirus Disease 2019 (COVID-19) CT Findings: A Systematic Review and Meta-analysis. J. Am. Coll. Radiol. 2020. Doi: 10.1016/j.jacr.2020.03.006. 
31. Zheng Z, Peng F, Xu B, Zhao J, Liu H, Peng J, Li Q, Jiang C, Zhou Y, Liu S, Ye C, Zhang P, Xing Y, Guo $\mathrm{H}$, Tang W. Risk factors of critical \& mortal COVID-19 cases: A systematic literature review and metaanalysis. J. Infect. 2020. Doi: 10.1016/j.jinf.2020.04.021.

32. Huang J, Cheng A, Lin S, Zhu Y, Chen G. Individualized prediction nomograms for disease progression in mild COVID-19. J. Med. Virol. 2020. Doi: 10.1002/jmv.25969.

33. Hu L, Chen S, Fu Y, Gao Z, Long H, Wang JM, Ren HW, Zuo Y, Li H, Wang J, Xu QB, Yu WX, Liu J, Shao C, Hao JJ, Wang CZ, Ma Y, Wang Z, Yanagihara R, Deng Y. Risk Factors Associated with Clinical Outcomes in 323 COVID-19 Hospitalized Patients in Wuhan, China. Clin. Infect. Dis. 2020. Doi: 10.1093/cid/ciaa539.

34. Zhang J, Yu M, Tong S, Liu LY, Tang LV. Predictive factors for disease progression in hospitalized patients with coronavirus disease 2019 in Wuhan, China. J. Clin. Virol. 2020; 127: 104392.

35. Yao XH, He ZC, Li TY, Zhang HR, Wang Y, Mou H, Guo Q, Yu SC, Ding YQ, Liu XD, Ping YF, Bian XW. Pathological evidence for residual SARS-CoV-2 in pulmonary tissues of a ready-for-discharge patient. Cell. Res. 2020. Doi: 10.1038/s41422-020-0318-5.

\section{Tables}

Table 1. Demographic and epidemiological characteristics 


\begin{tabular}{|c|c|c|c|c|}
\hline & $\begin{array}{l}\text { PCR } \\
\text { confirmed } \\
(\mathrm{N}=114)\end{array}$ & $\begin{array}{l}\text { Serology } \\
\text { confirmed } \\
(N=17)\end{array}$ & $\begin{array}{l}\text { Clinically } \\
\text { diagnosed } \\
(\mathrm{N}=21)\end{array}$ & $\begin{array}{l}P \\
\text { value }\end{array}$ \\
\hline Gender, n (\%) & & & & 0.221 \\
\hline Male & $58(50.9)$ & $5(29.4)$ & $9(42.9)$ & \\
\hline Female & $56(49.1)$ & $12(70.6)$ & $12(57.1)$ & \\
\hline Age, year & $58.8 \pm 12.9$ & $67.8 \pm 12.8^{*}$ & $59.3 \pm 14.3$ & 0.032 \\
\hline $\mathrm{BMI}, \mathrm{kg} / \mathrm{m}^{2}$ & $23.4(4.4)$ & $27.1(5.6)$ & $26.8(6.6)$ & 0.102 \\
\hline Time from onset to the first PCR test & $7.5(9.0)$ & $13.0(13.0)$ & $9.0(12.0)$ & 0.216 \\
\hline $\begin{array}{l}\text { Time from onset to the first negative } \\
\text { PCR results }\end{array}$ & $24.3 \pm 9.1$ & $12.2 \pm 8.4^{*}$ & $10.4 \pm 7.1^{*}$ & 0.000 \\
\hline Time from onset to admission & $15.0(10.0)$ & $16.0(12.0)$ & $15.0(7.0)$ & 0.842 \\
\hline Time from onset to diagnosis & $8.0(10.0)$ & $35.0(9.0)$ * & / & 0.000 \\
\hline Exposure history $\$$ n (\%) & $50(43.9)$ & $6(35.3)$ & $9(42.9)$ & 0.824 \\
\hline \multicolumn{5}{|l|}{ Comorbidity, n (\%) } \\
\hline Hypertension & $39(34.2)$ & $11(64.7)$ * & $11(52.4)$ & 0.031 \\
\hline Diabetes mellitus & $15(13.2)$ & $5(29.4)$ & $3(14.3)$ & 0.252 \\
\hline Asthma & $0(0.0)$ & $0(0.0)$ & $0(0.0)$ & / \\
\hline COPD & $7(6.1)$ & $0(0.0)$ & $1(4.8)$ & 0.838 \\
\hline $\mathrm{CHD}$ & $11(9.6)$ & $3(17.6)$ & $3(14.3)$ & 0.462 \\
\hline Renal insufficiency & $1(0.9)$ & $0(0.0)$ & $2(9.5)$ & 0.083 \\
\hline Hepatic disease & $5(4.4)$ & $0(0.0)$ & $0(0.0)$ & 1.000 \\
\hline Cancer & $2(1.8)$ & $1(5.9)$ & $1(4.8)$ & 0.260 \\
\hline Neural disease & $3(2.6)$ & $2(11.8)$ & $0(0.0)$ & 0.152 \\
\hline \multicolumn{5}{|l|}{ Smoking history, n (\%) } \\
\hline None & $104(91.2)$ & $14(87.5)$ & $18(85.7)$ & \multirow[t]{3}{*}{0.277} \\
\hline Current smoker & $4(3.5)$ & $2(12.5)$ & $2(9.5)$ & \\
\hline Former smoker & $6(5.3)$ & $0(0.0)$ & $1(4.8)$ & \\
\hline
\end{tabular}

Data are represented as the median (interquartile range) or mean \pm standard deviation (SD) except for particular specifications. ${ }^{*} P<0.05$ compared with polymerase chain reaction (PCR)-confirmed cases, ${ }^{\#} P<$ 
0.05 compared with serology-confirmed cases. \$ Wuhan residency and travel history were excluded. BMI, body mass index; COPD, chronic obstructive pulmonary disease; CHD, coronary heart disease.

Table 2. Clinical and imaging characteristics 


\begin{tabular}{|c|c|c|c|c|}
\hline & $\begin{array}{l}\text { PCR } \\
\text { confirmed } \\
(\mathrm{N}=114)\end{array}$ & $\begin{array}{l}\text { Serology } \\
\text { confirmed } \\
(\mathrm{N}=17)\end{array}$ & $\begin{array}{l}\text { Clinically } \\
\text { diagnosed } \\
(\mathrm{N}=21)\end{array}$ & $\begin{array}{l}P \\
\text { value }\end{array}$ \\
\hline \multicolumn{5}{|l|}{ Symptoms, n (\%) } \\
\hline Fever & $98(86.0)$ & $15(88.2)$ & $12(57.1)$ *\# & 0.010 \\
\hline Cough & $92(80.7)$ & $14(82.4)$ & $19(90.5)$ & 0.594 \\
\hline Fatigue & $70(61.4)$ & $12(70.6)$ & $15(71.4)$ & 0.635 \\
\hline Anorexia & $59(51.8)$ & $11(64.7)$ & $12(57.1)$ & 0.608 \\
\hline Chest tightness & $67(58.8)$ & $13(76.5)$ & $11(52.4)$ & 0.302 \\
\hline Chest pain & 36 (31.6) & 9 (52.9) & 11 (52.4) & 0.071 \\
\hline Dyspnea & $40(35.1)$ & $9(52.9)$ & $12(57.1)$ & 0.090 \\
\hline Chest pain+dyspnea & $15(13.2)$ & $7(41.2)$ * & $8(38.1)$ * & 0.002 \\
\hline Headache & $22(19.3)$ & $5(29.4)$ & $6(28.6)$ & 0.428 \\
\hline Abdominal pain & $17(14.9)$ & $4(23.5)$ & $4(19.0)$ & 0.579 \\
\hline Diarrhea & $30(26.3)$ & $3(17.6)$ & $5(23.8)$ & 0.819 \\
\hline Nausea & $21(18.4)$ & $5(29.4)$ & $1(4.8)$ & 0.132 \\
\hline Vomit & $12(10.5)$ & $5(29.4)$ * & $0(0.0)$ & 0.016 \\
\hline Nasal symptoms & $4(3.5)$ & $1(5.9)$ & $1(4.8)$ & 0.468 \\
\hline \multicolumn{5}{|c|}{ Severity when admission } \\
\hline mild & $1(0.9)$ & $0(0.0)$ & $0(0.0)$ & \multirow[t]{4}{*}{0.046} \\
\hline common & $73(64.0)$ & $6(35.3)$ & $16(76.2)$ & \\
\hline severe & $39(34.2)$ & $11(64.7)$ & $4(19.0)$ & \\
\hline critical & $1(0.9)$ & $0(0.0)$ & $1(4.8)$ & \\
\hline \multicolumn{5}{|c|}{ Imaging characteristics, N (\%) } \\
\hline Pleural effusion & $2(1.9)$ & $2(12.5)$ * & $2(11.1)$ * & 0.030 \\
\hline Pleural thickening & $35(32.7)$ & $5(31.2)$ & $5(27.8)$ & 0.953 \\
\hline Consolidation & $14(12.6)$ & $4(23.5)$ & $4(22.2)$ & 0.269 \\
\hline Ground glass opacity & $105(94.6)$ & $15(88.2)$ & $15(83.3)$ & 0.107 \\
\hline Cord shadow & $50(45.0)$ & $5(29.4)$ & $12(66.7)$ & 0.084 \\
\hline Bilateral involved & $\begin{array}{r}105(94.6) \\
\text { Page 15/18 }\end{array}$ & $16(94.1)$ & $18(90.0)$ & 0.118 \\
\hline
\end{tabular}




\begin{tabular}{|lllll|}
\hline Number of affected lung lobes & $4.0(3.0)$ & $5.0(1.0)$ & $5.0(2.0)$ & 0.069 \\
\hline Hospital time & $22.4 \pm 11.1$ & $28.8 \pm 10.6^{*}$ & $13.0 \pm 7.8^{* \#}$ & 0.000 \\
\hline Mortality & $1(0.9)$ & $0(0.0)$ & $1(4.8)$ & 0.439 \\
\hline Disease progression & $4(3.5)$ & $3(17.6)^{*}$ & $2(10.0)$ & 0.041 \\
\hline $\begin{array}{l}\text { Time from admission to cessation of } \\
\text { oxygen support }\end{array}$ & $17.0 \pm 13.9$ & $28.9 \pm 9.9^{*}$ & $12.0 \pm 8.3^{\#}$ & 0.000 \\
\hline
\end{tabular}

Data are represented as the median (interquartile range) or mean \pm standard deviation (SD) except for particular specifications. ${ }^{*} P<0.05$ compared with PCR confirmed cases, ${ }^{\#} P<0.05$ compared with serology confirmed cases.

Table 3. Laboratory indicators 


\begin{tabular}{|c|c|c|c|c|}
\hline & $\begin{array}{l}\text { PCR confirmed } \\
(\mathrm{N}=114)\end{array}$ & $\begin{array}{l}\text { Serology confirmed } \\
(\mathrm{N}=17)\end{array}$ & $\begin{array}{l}\text { Clinically diagnosed } \\
(\mathrm{N}=21)\end{array}$ & $P$ value \\
\hline CRP, mg/L & $4.1(23.7)$ & $21.6(72.1)$ * & $13.7(17.6)$ & 0.010 \\
\hline Neutrophil, $\times 10^{\wedge} 9 / \mathrm{L}$ & $3.6(2.4)$ & $3.7(2.7)$ & $4.0(2.6)$ & 0.425 \\
\hline Lymphocyte, $\times 10^{\wedge} 9 / \mathrm{L}$ & $1.4 \pm 0.5$ & $1.1 \pm 0.4$ & $1.4 \pm 0.5$ & 0.160 \\
\hline NLR & $2.8(1.5)$ & $3.7(2.1)$ * & $2.2(3.5)$ & 0.016 \\
\hline $\mathrm{Hb}, \mathrm{g} / \mathrm{L}$ & $126.3 \pm 15.6$ & $113.5 \pm 17.6 *$ & $121.7 \pm 18.3$ & 0.009 \\
\hline $\mathrm{PLT}, \times 10^{\wedge} 9 / \mathrm{L}$ & $256.4 \pm 98.0$ & $286.6 \pm 116.2$ & $283.8 \pm 97.0$ & 0.312 \\
\hline ALT, U/L & $23.5(27.0)$ & $16.0(14.5)$ & $22.5(20.2)$ & 0.372 \\
\hline AST, U/L & $25.5(15.3)$ & $21.0(18.0)$ & $22.0(10.0)$ & 0.124 \\
\hline $\mathrm{TB}, \mu \mathrm{mol} / \mathrm{L}$ & $7.6(5.1)$ & $10.1(6.8)$ * & $7.5(4.1)$ & 0.007 \\
\hline Alb, g/L & $37.0 \pm 6.7$ & $33.4 \pm 4.9 *$ & $34.0 \pm 3.7$ & 0.023 \\
\hline $\mathrm{Scr}, \mu \mathrm{mol} / \mathrm{L}$ & $68.5(23.3)$ & $72.0(34.5)$ & $67.0(39.8)$ & 0.264 \\
\hline D-dimer, $\mu \mathrm{g} / \mathrm{ml}$ & $0.6(0.8)$ & $1.4(1.4)$ * & $0.8(0.9)$ & 0.005 \\
\hline $\mathrm{Fg}, \mathrm{g} / \mathrm{L}$ & $4.6 \pm 1.6$ & $5.5 \pm 1.4^{*}$ & $5.3 \pm 1.9$ & 0.049 \\
\hline Troponin, ng/ml & $2.5(3.8)$ & $4.5(10.8)$ * & $2.5(4.9)$ & 0.049 \\
\hline CK-MB, U/L & $0.6(0.7)$ & $0.7(0.7)$ & $0.7(1.2)$ & 0.128 \\
\hline $\mathrm{IL}-1 \beta, \mathrm{pg} / \mathrm{ml}$ & $5.0(0.0)$ & $5.0(0.1)$ & $5.0(0.0)$ & 0.475 \\
\hline $\mathrm{IL}-2 \mathrm{R}, \mathrm{U} / \mathrm{ml}$ & $483.5(350.0)$ & $617.0(363.5)$ & $602.5(724.5)$ & 0.275 \\
\hline IL-6, pg/ml & $3.5(5.1)$ & $10.0(19.9)$ * & $3.5(8.8)$ & 0.007 \\
\hline IL-8, pg/ml & $9.1(10.2)$ & $13.5(15.6)$ * & $6.8(8.1)$ & 0.031 \\
\hline IL-10, pg/ml & $5.0(0.0)$ & $5.0(0.0)$ & $5.0(0.0)$ & 0.691 \\
\hline TNF-a, pg/ml & $7.8(4.0)$ & $9.1(5.9)$ & $8.2(4.9)$ & 0.132 \\
\hline
\end{tabular}

Data were represented as median (interquartile range) or mean \pm standard deviation (SD) except for particular specifications. ${ }^{*} P<0.05$ compared with PCR confirmed cases. CRP, C-reactive protein; NLR, neutrophil-to-lymphocyte ratio; $\mathrm{Hb}$, hemoglobin; PLT, platelet; ALT, Alanine transaminase; AST, aspertate aminotransferase; TB, total bilirubin; Alb, albumin; Scr, serum creatine; Fg, fibrinogen; CK-MB, creatine kinase isoenzyme; IL, interleukin; TNF-a, tumor necrosis factor a.

\section{Figures}




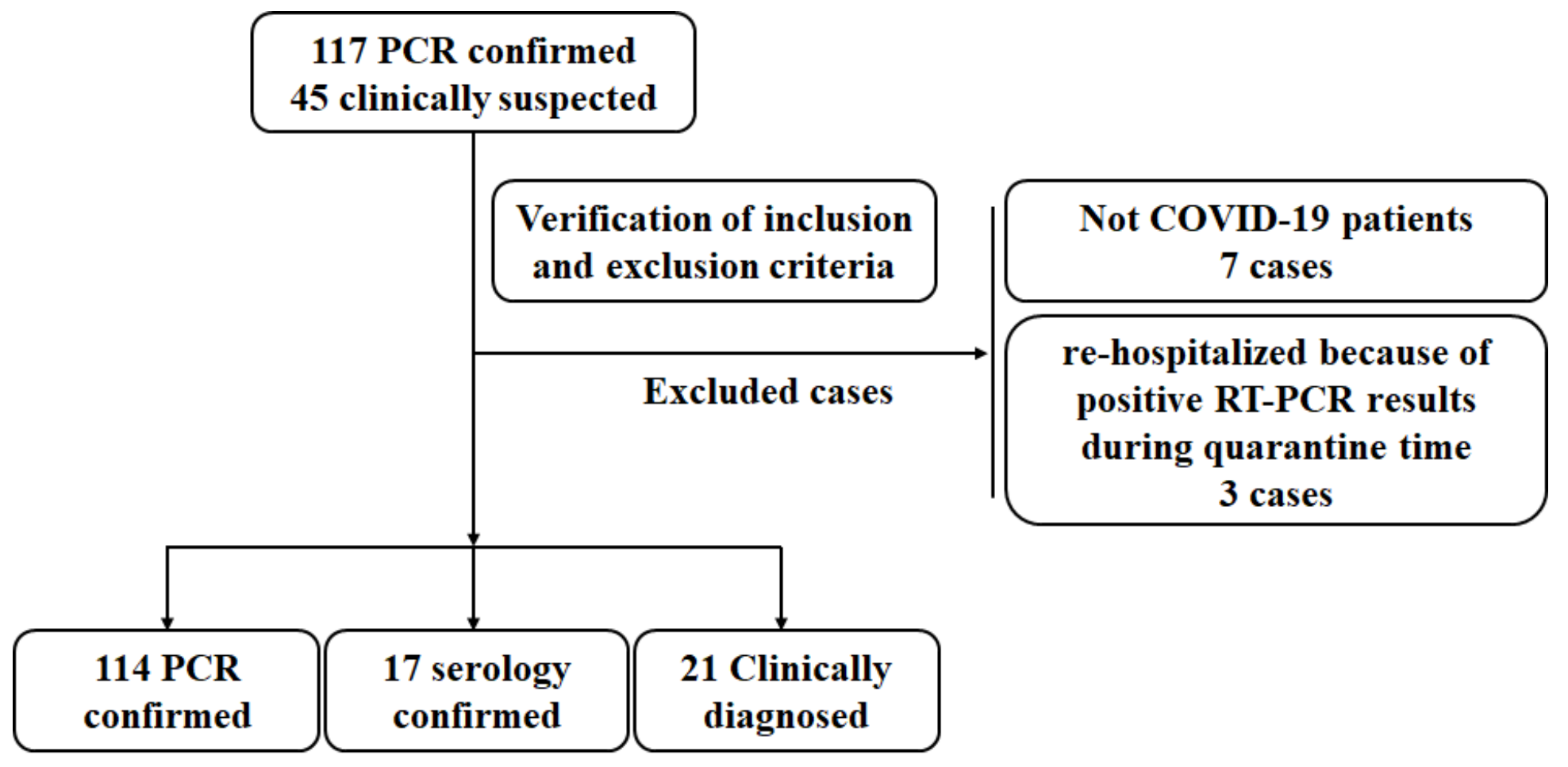

Figure 1

Flowchart of the study. 